\title{
Use of the Bruker AXS SMART BREEZETM System for Macromolecular X-ray Data Collection
}

\author{
Christiana Standler, G. Blake Overson, Cody A. Black, Guizella A. Rocabado, and Bruce R. Howard* \\ Department of Physical Science, Southern Utah University, Cedar City, UT \\ Students: christystandler@yahoo.com,goverson4@gmail.com,codyadamblack@gmail.com,guizella.rocabado@gmail.com \\ Mentor: howard@suu.edu*
}

\begin{abstract}
The Bruker AXS SMART BREEZE ${ }^{\mathrm{TM}}$ system is a single-crystal X-ray diffractometer designed to collect data from crystals of small organic or inorganic compounds. It is typically equipped with a Molybdenum-anode sealed tube to facilitate data collection from small unit cells. We recently acquired this system, but chose to have it installed with a copper-anode sealed tube with the hope of using it to collect data from larger unit cells such as those found in crystals of proteins or other macromolecules. This is the first and only BREEZE ${ }^{\mathrm{TM}}$ system installed by Bruker AXS with a copper-anode to date. Here we show that this system is capable of efficiently collecting quality X-ray diffraction data from crystals of the enzymes lysozyme and xylanase. This capability to collect diffraction data from both macromolecular and small-molecule crystals greatly expands the scope of undergraduate research projects that can be addressed using this instrument.
\end{abstract}

\section{KEYWORDS}

X-ray; Diffraction; Crystallography; Diffractometer; Protein; Enzyme; Crystal; Structure

\section{INTRODUCTION}

X-rays were discovered in 1895 by Wilhelm Roentgen at Wurzburg University in Germany, resulting in his winning the Nobel Prize in Physics in 1901. ${ }^{1}$ The first diffraction of X-rays from crystals was reported in 1912 by Max von Laue, ${ }^{2}$ and a description of the diffraction as reflections from internal planes of electron density was provided soon after by Sir William Lawrence Bragg. ${ }^{3}$ These contributions resulted in Nobel Prizes in Physics for von Laue and Bragg in 1914 and 1915 respectively. ${ }^{1}$ The first crystal structure reported was for sodium chloride, ${ }^{4}$ and since then this technique has become one of the most effective methods for defining the three-dimensional atomic structures of molecules and coordination compounds.

X-ray crystallography involves the collection of diffracted rays and analysis of the resulting patterns to generate an electron density map of the molecules in the crystal. X-ray crystallography allows for the imaging of particles as small as the wavelength of the Xrays used, which is often about one to two Angstroms $(\AA)$. The low-resolution data are found at low scattering angles, while the higher resolution data diffract to higher angles. This data must be analyzed, and phase information for the diffracted rays must be determined. This is often provided by the analysis of the influence of heavy atoms within the crystal. For excellent discussions of these processes, the reader is referred to the work of Rhodes and Rupp. ${ }^{5,6}$

Molecules must be in a crystalline structure for X-rays to be successfully diffracted and molecular models to be determined. This is a challenge in the case of protein molecules because many are difficult to crystalize, as they do not naturally occur in crystalline form. Protein crystals are also fragile because they require a high level of hydration (typically $40 \%-60 \%$ water by volume) in order to maintain a biologically relevant structure in the crystal. Despite these challenges, X-ray crystallography is arguably the most common method used to determine three dimensional models of protein molecules. ${ }^{7}$ Of the 123,021 structures deposited in the Protein Data Bank as of September 2016, 109,963 (89.4\%) were solved with X-ray crystallography.

The first X-ray crystal structure of a protein was reported for myoglobin ${ }^{8,9}$, which introduced the scientific community to the complexities of protein structure and indicated that proteins could adopt specific three-dimensional folds. It also provided insight into how a specific conformation of protein could drive function. The second protein structure solved was hemoglobin, which showed how proteins can work cooperatively to carry out their biological function. ${ }^{10,11}$ 
The Physical Science Department at Southern Utah University (SUU) recently purchased a Bruker AXS SMART BREEZETM System (Figure 1). It is comprised of a stand-alone cabinet with leaded glass windows enclosing a sealed fine-focus X-ray tube which is water-cooled. The crystal is mounted on a goniometer head with a fixed-chi geometry. Data are collected on a BREEZETM CCD detector with an active area of $62 \mathrm{~mm}$ x $62 \mathrm{~mm}$, fitted with a Peltier thermoelectric cooling chip maintained at $-25{ }^{\circ} \mathrm{C}$ to reduce background noise. The system is equipped with an Oxford Cryostream 700 in order to control sample temperature and to allow data collection at cryogenic temperatures (ranges from 80 to 400 Kelvin).

Although this system is designed to collect data from crystals with small unit cells, we wanted to evaluate its effectiveness for use with larger unit cells such as those found in protein crystals. When our system was installed, we selected a copper-anode sealed tube for an X-ray source. This is the first and only SMART BREEZETM system installed by Bruker AXS with a copper tube. ${ }^{12}$ We $^{\text {TM }}$ wanted to use copper- $\mathrm{K}_{\alpha}$ radiation because we hoped to be able to use the system for protein crystals in addition to small molecules. To confirm this expectation, we chose hen egg white lysozyme to carry out our crystallization and diffraction experiments. Hen egg white lysozyme was first isolated and crystallized in $1944 .{ }^{13}$ It was the first enzyme to have its structure determined, ${ }^{14}$ although the structure wasn't refined until nearly a decade later. ${ }^{15}$ Because details of this protein have been studied and very well defined, including crystallization conditions, lysozyme provided a good target to carry out our evaluation experiments. We also tested another available protein standard: xylanase from Trichoderma longibrachiatum.16, 17
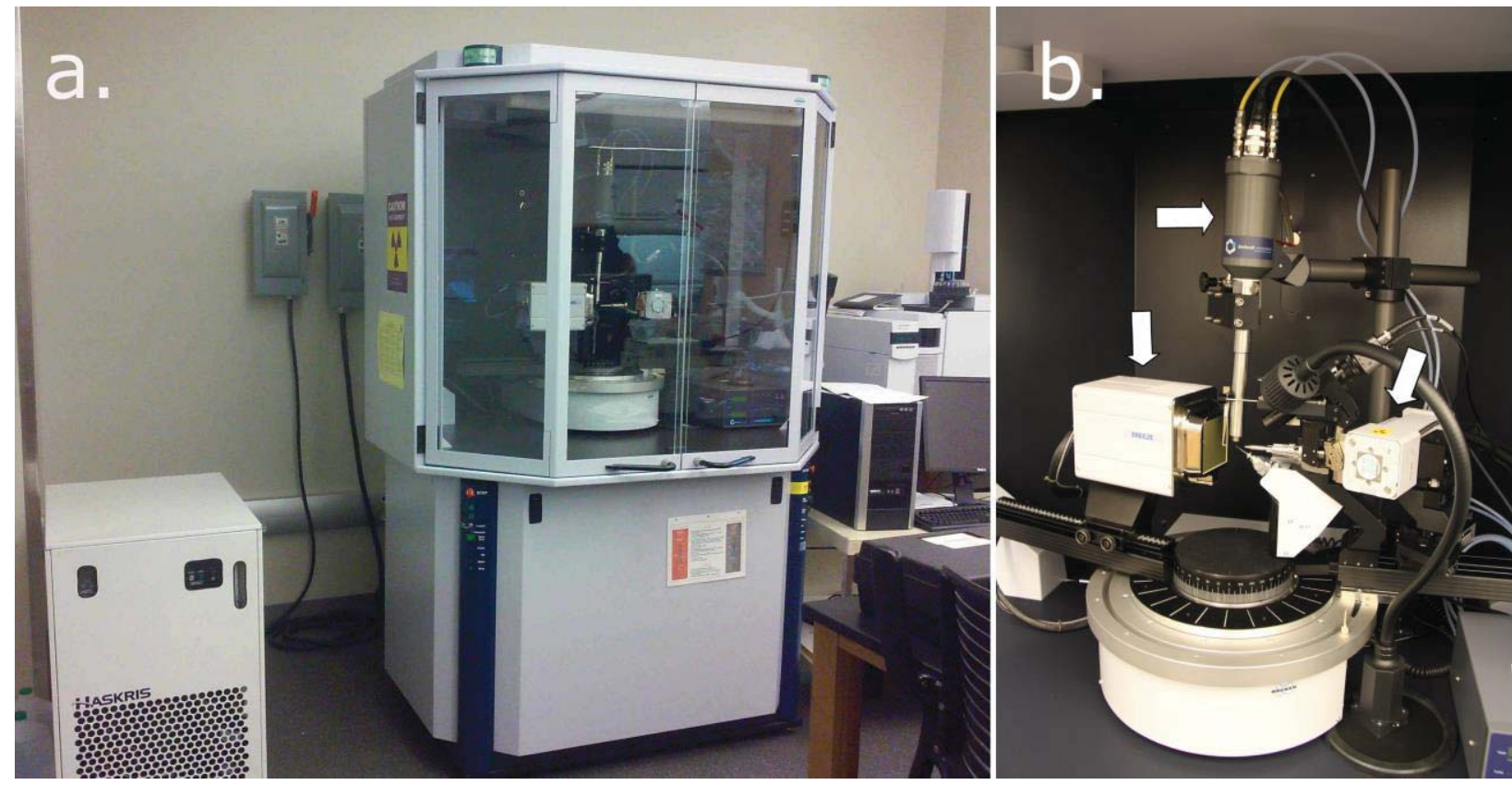

Figure 1. a. SMART BREEZETM System in the lab with Haskris water-chiller on the left to cool the X-ray tube. b. Close-up view inside of the cabinet. The BREEZETM CCD detector is on the left, the sealed X-ray tube on the right, and the Cryostream at the top (white arrows).

\section{MATERIALS, METHODS AND RESULTS}

\section{Crystallization}

Hen egg white (HEW) lysozyme was purchased from Sigma-Aldrich in the form of a lyophilized powder and resuspended in $0.1 \mathrm{M}$ sodium acetate, $\mathrm{pH} 4.8$, at a final concentration of $75 \mathrm{mg} / \mathrm{ml}$. Crystallization was carried out in sitting drops using a reservoir solution consisting of $10 \% \mathrm{w} / \mathrm{v} \mathrm{NaCl}, 0.1 \mathrm{M}$ sodium acetate $\mathrm{pH} 4.8,25 \% \mathrm{v} / \mathrm{v}$ ethylene glycol. ${ }^{18,19} \mathrm{For}$ each drop, $7 \mu \mathrm{l}$ of protein solution and $3 \mu \mathrm{l}$ of reservoir solution were mixed together and allowed to equilibrate at room temperature with $1 \mathrm{ml}$ of reservoir solution via vapor diffusion (Figure 2).

Xylanase was purchased from Hampton Research as a concentrated solution containing the enzyme at $36 \mathrm{mg} / \mathrm{ml}, 0.18 \mathrm{M} \mathrm{Na} / \mathrm{K}$ phosphate $\mathrm{pH} 7$, and 43\% w/v glycerol. Crystallization was carried out in sitting drops using a reservoir solution containing $1.3 \mathrm{M}$ ammonium sulfate, $200 \mathrm{mM}$ bicine $\mathrm{pH}$ 9. The protein solution contained $18 \mathrm{mg} / \mathrm{ml}$ xylanase, $21.5 \%$ glycerol, $90 \mathrm{mM} \mathrm{Na} / \mathrm{K}$ phosphate $\mathrm{pH} 7$. For each drop, $2 \mu \mathrm{l}$ of protein solution was added to $1.4 \mu \mathrm{l}$ of reservoir solution and $0.6 \mu \mathrm{l}$ of $1 \mathrm{M} \mathrm{NaI}$, and allowed to equilibrate at room temperature in vapor contact with $1 \mathrm{ml}$ of reservoir solution (Figure 3). ${ }^{17}$ 


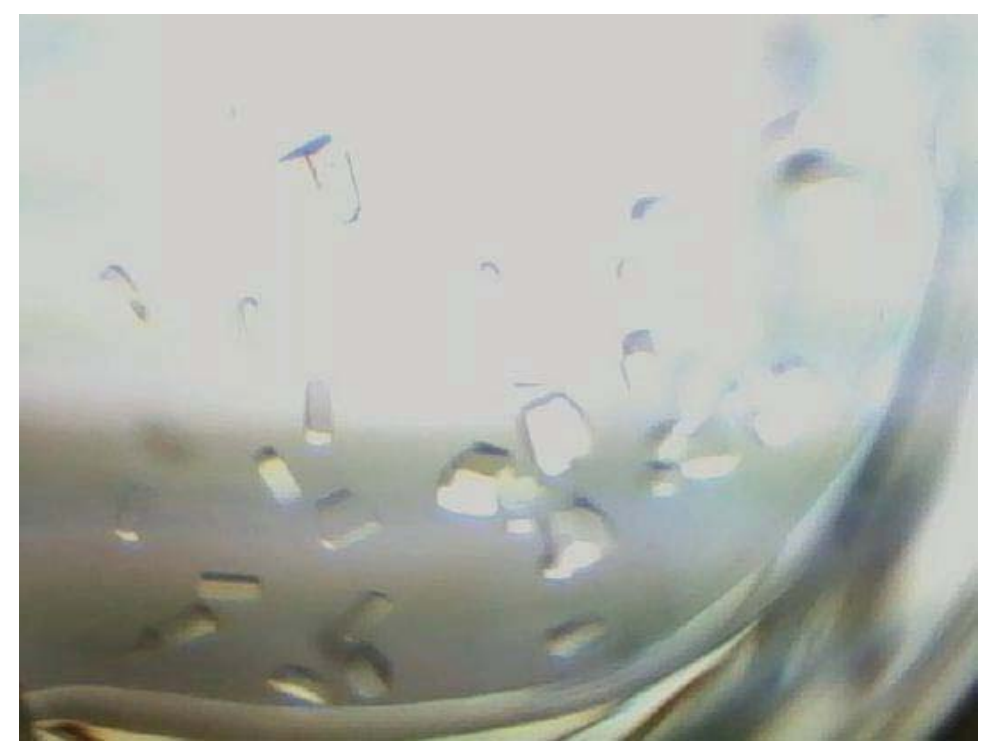

Figure 2. Tetragonal crystals of Hen egg white lysozyme.

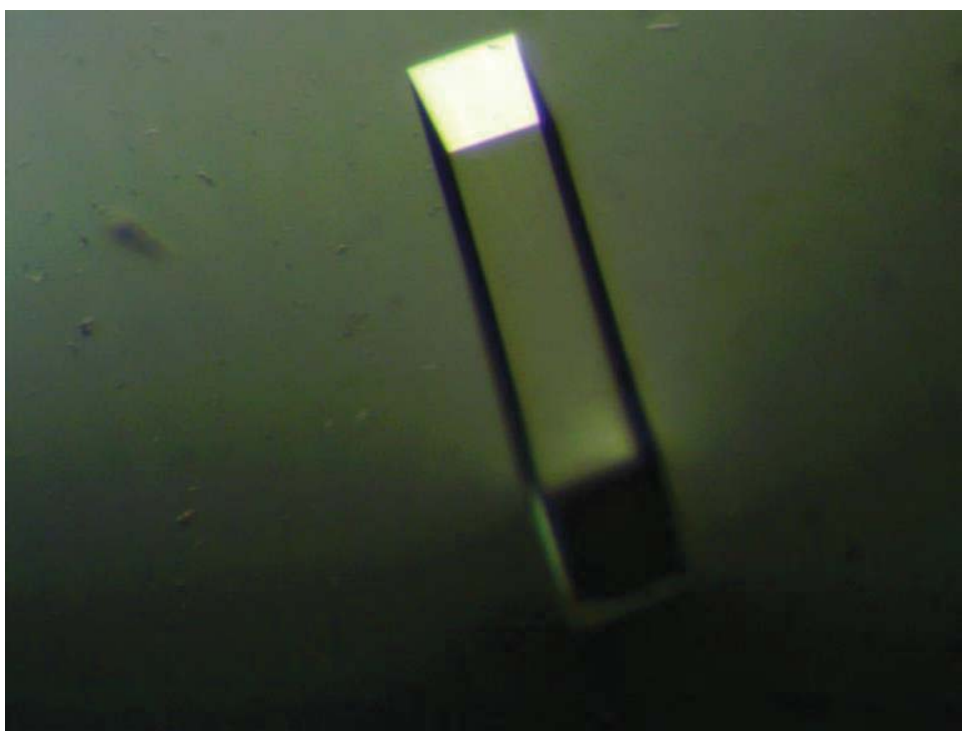

Figure 3. Orthorhombic crystal of Xylanase used for data collection.

X-ray data collection and processing

Crystals of lysozyme were suspended in nylon loops and cooled quickly by placement in a stream of dried nitrogen gas chilled to a temperature of 100 Kelvin (Oxford Cryostream 700, Oxford Cryosystems). X-rays were generated by a $1.5 \mathrm{~kW}$ fine-focus copper sealed tube running at $40 \mathrm{kV}$ and $30 \mathrm{~mA}$ (Siemens, Germany). A collimated, monochromatic, $1.54-\AA$ X-ray beam $300 \mu \mathrm{m}$ in diameter was directed through the crystal and into a lead beamstop. Diffraction data were collected on a BREEZE ${ }^{\mathrm{TM}}$ CCD detector (Bruker AXS).

An example of the diffraction data from a lysozyme crystal can be seen in Figure 4. A total of 2709 images were collected by oscillating the crystal in $0.5^{\circ}$ steps with 60 -second exposures to generate a highly redundant ( $\sim 40$-fold overall) dataset. The details of the data collection are listed in Table 1a. The diffraction data were indexed, integrated, scaled and merged using SAINT ${ }^{20}$ and SADABS. ${ }^{21}$ The X-ray data are listed in Table $2 \mathrm{a}$. 


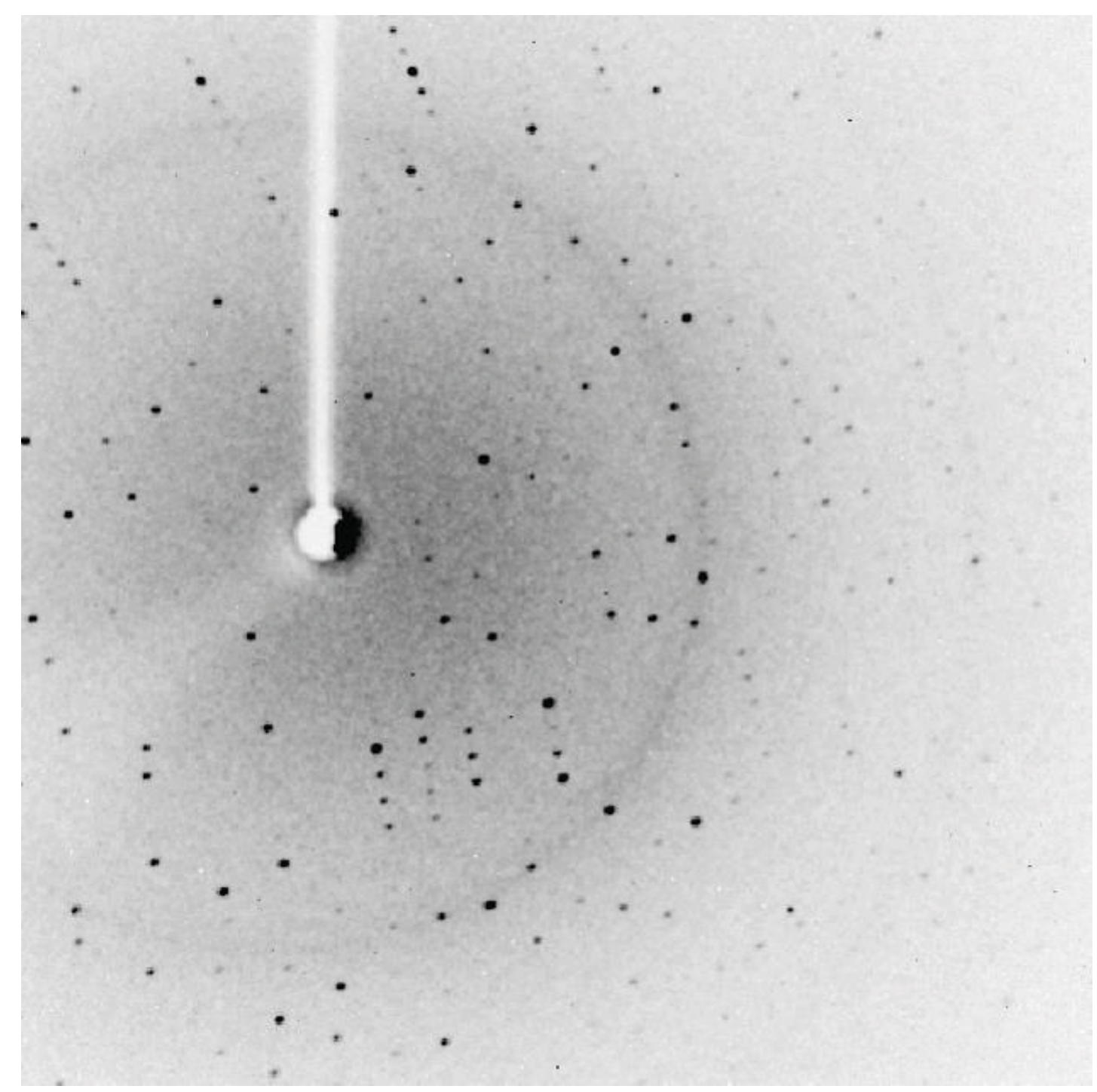

Figure 4. Example of diffraction data from a lysozyme crystal measuring approximately $0.2 \mathrm{~mm} \times 0.2 \mathrm{~mm} \times 0.1 \mathrm{~mm}$ in size. The image is a 60 second exposure with an oscillation angle of $0.5^{\circ}$. The right edge of the detector corresponds to a d-spacing of $\sim 1.8$ Angstroms.

\begin{tabular}{|c|c|c|c|c|c|c|c|c|c|}
\hline \multicolumn{9}{|c|}{ Table 1a. Lysozyme X-ray Data Collection } \\
\hline Axis & dist/mm & $20 /{ }^{\circ}$ & $\omega /{ }^{\circ}$ & $\varphi /{ }^{\circ}$ & $\chi /^{\circ}$ & Width $\left({ }^{\circ}\right)$ & Sweep $\left({ }^{\circ}\right)$ & Frames & Time (s) \\
\hline Omega & 50.386 & -14.5 & -199 & 257.5 & 54.7 & 0.5 & 188.5 & 377 & 60 \\
\hline Omega & 50.386 & 18 & -166.5 & 142.5 & 54.7 & 0.5 & 188.5 & 377 & 60 \\
\hline Omega & 50.386 & -17 & -201.5 & -100 & 54.7 & 0.5 & 61 & 122 & 60 \\
\hline Omega & 50.386 & 18 & -166.5 & -112.5 & 54.7 & 0.5 & 165.5 & 331 & 60 \\
\hline Omega & 50.386 & -19.5 & -202.05 & -317.5 & 54.7 & 0.5 & 185.5 & 371 & 60 \\
\hline Omega & 50.386 & -14.5 & -199 & 45 & 54.7 & 0.5 & 188.5 & 377 & 60 \\
\hline Omega & 50.386 & 13 & -171.5 & -27.5 & 54.7 & 0.5 & 188.5 & 377 & 60 \\
\hline Omega & 50.386 & 18 & -166.5 & -347.5 & 54.7 & 0.5 & 188.5 & 377 & 60 \\
\hline
\end{tabular}


Table 2a. Lysozyme X-ray Data Statistics

\begin{tabular}{|c|c|c|c|c|}
\hline Resolution ( $(\AA)$ & $\%$ Complete & Redundancy & Mean I/ $\sigma$ & $\mathbf{R}_{\text {(int) }}$ \\
\hline $19.75-5.11$ & 97.3 & 78.51 & 80.48 & 0.0601 \\
\hline $5.11-4.00$ & 100 & 64.11 & 76.49 & 0.0581 \\
\hline $4.00-3.47$ & 100 & 59.1 & 67.27 & 0.0683 \\
\hline $3.47-3.14$ & 100 & 57.24 & 58.03 & 0.0764 \\
\hline $3.14-2.90$ & 100 & 52.84 & 41.48 & 0.1051 \\
\hline $2.90-2.72$ & 100 & 49.02 & 29.38 & 0.1402 \\
\hline $2.72-2.58$ & 100 & 46.73 & 25.49 & 0.163 \\
\hline $2.58-2.46$ & 100 & 44.33 & 22.33 & 0.1853 \\
\hline $2.46-2.36$ & 100 & 42.58 & 19.4 & 0.2122 \\
\hline $2.36-2.27$ & 100 & 40.8 & 18.45 & 0.2236 \\
\hline $2.27-2.19$ & 100 & 39.24 & 15.02 & 0.2646 \\
\hline $2.19-2.12$ & 100 & 37.42 & 14.24 & 0.2878 \\
\hline $2.12-2.06$ & 100 & 35 & 12.07 & 0.3251 \\
\hline $2.06-2.01$ & 100 & 31.81 & 10.12 & 0.3791 \\
\hline $2.01-1.96$ & 100 & 26.89 & 7.87 & 0.4374 \\
\hline $1.96-1.92$ & 100 & 23.64 & 6.15 & 0.4698 \\
\hline $1.92-1.88$ & 100 & 18.89 & 5.2 & 0.5097 \\
\hline $1.88-1.84$ & 100 & 12.53 & 3.58 & 0.5991 \\
\hline $1.84-1.80$ & 99.6 & 8.07 & 2.62 & 0.6567 \\
\hline $19.75-1.80$ & 99.8 & 40.27 & 26.62 & 0.128 \\
\hline
\end{tabular}

A xylanase crystal (Figure 3) measuring approximately $0.15 \mathrm{~mm} \times 0.15 \mathrm{~mm} \times 0.85 \mathrm{~mm}$ was transferred to a cryoprotected solution consisting of $1.3 \mathrm{M}$ ammonium sulfate, $200 \mathrm{mM}$ bicine $\mathrm{pH} 9,30 \% \mathrm{v} / \mathrm{v}$ glycerol and $175 \mathrm{mM} \mathrm{NaI}$ for a few seconds and then flash-cooled by plunging into liquid nitrogen. This crystal was held at $100 \mathrm{~K}$ for data collection as described above. For this crystal we wanted to test the efficiency of the system by collecting shorter exposures and limiting the data collection time to five hours (Table 1b). A shortened data collection time would allow the collection of multiple data sets per day, and would support the feasibility of providing a data collection opportunity to each student group in an academic laboratory. Such efficient data collection on a protein standard like xylanase would allow the incorporation of a crystallography section into an academic biochemistry laboratory. As shown in Table $2 \mathbf{b}$, we were able to collect a complete dataset to $1.78 \AA$ resolution with an overall redundancy of 13.5, an $\sim 13$-fold mean signal to noise ratio, and reasonable integration statistics. 
Table 1b. Xylanase X-ray Data collection

\begin{tabular}{|c|c|c|c|c|c|c|c|c|c|}
\hline Axis & dist $/ \mathrm{mm}$ & $20 /{ }^{\circ}$ & $\omega /{ }^{\circ}$ & $\varphi /{ }^{\circ}$ & $\chi /^{\circ}$ & Width $\left(^{\circ}\right)$ & Sweep $\left({ }^{\circ}\right)$ & Frames & Time $(\mathrm{s})$ \\
\hline Omega & 50.270 & 25.31 & -158.69 & 28.00 & 54.73 & 0.50 & 188.00 & 376 & 10 \\
\hline Omega & 50.270 & 25.31 & -158.69 & -23.18 & 54.73 & 0.50 & 188.00 & 376 & 10 \\
\hline Phi & 50.270 & 24.21 & -159.79 & -127.00 & 54.73 & 0.50 & 150.00 & 300 & 10 \\
\hline Omega & 50.270 & 25.31 & -158.69 & 102.96 & 54.73 & 0.50 & 188.00 & 376 & 10 \\
\hline Omega & 50.270 & 25.31 & -158.69 & -195.63 & 54.73 & 0.50 & 188.00 & 376 & 10 \\
\hline
\end{tabular}

\begin{tabular}{|c|c|c|c|c|}
\hline \multicolumn{5}{|c|}{ Table 2b. Xylanase X-ray Data statistics } \\
\hline Resolution & $\%$ Complete & Redundancy & Mean I/ $\sigma$ & $\mathbf{R}_{\text {(int) }}$ \\
\hline $58.78-7.74$ & 99.3 & 18.09 & 41.28 & 0.0660 \\
\hline $7.74-5.03$ & 99.9 & 17.56 & 32.92 & 0.0776 \\
\hline $5.03-3.94$ & 100.0 & 17.27 & 37.21 & 0.0608 \\
\hline $3.94-3.42$ & 100.0 & 17.25 & 33.77 & 0.0717 \\
\hline $3.42-3.09$ & 100.0 & 17.19 & 26.45 & 0.0940 \\
\hline $3.09-2.86$ & 100.0 & 16.44 & 20.68 & 0.1212 \\
\hline $2.86-2.68$ & 100.0 & 15.65 & 15.89 & 0.1528 \\
\hline $2.68-2.55$ & 100.0 & 14.93 & 13.16 & 0.1796 \\
\hline $2.55-2.43$ & 100.0 & 14.28 & 11.09 & 0.2064 \\
\hline $2.43-2.34$ & 100.0 & 13.66 & 9.55 & 0.2361 \\
\hline $2.34-2.25$ & 100.0 & 13.10 & 8.46 & 0.2615 \\
\hline $2.25-2.18$ & 100.0 & 12.77 & 7.41 & 0.2950 \\
\hline $2.18-2.11$ & 100.0 & 12.27 & 6.88 & 0.3068 \\
\hline $2.11-2.06$ & 100.0 & 11.90 & 5.68 & 0.3471 \\
\hline $2.06-2.01$ & 100.0 & 11.58 & 5.40 & 0.3585 \\
\hline $2.01-1.96$ & 100.0 & 11.26 & 4.35 & 0.4224 \\
\hline $1.96-1.92$ & 100.0 & 11.01 & 3.79 & 0.4743 \\
\hline $1.92-1.88$ & 100.0 & 10.67 & 3.08 & 0.5382 \\
\hline $1.88-1.84$ & 100.0 & 10.41 & 2.55 & 0.5948 \\
\hline $1.84-1.81$ & 100.0 & 10.21 & 2.27 & 0.6356 \\
\hline $1.81-1.78$ & 100.0 & 9.96 & 1.96 & 0.6833 \\
\hline $58.78-1.78$ & 100.0 & 13.50 & 12.81 & 0.1500 \\
\hline
\end{tabular}




\section{Crystal structure solution and refinement of lysozyme}

The unit cell parameters were similar to a tetragonal crystal form of HEW lysozyme with the same space group that was deposited in 1975 by R. Diamond (PDB ID: $1 \mathrm{LYZ}){ }^{7}$ The space group for this entry is $\mathrm{P} 4_{3} 2_{1} 2$ with cell dimensions of $\mathrm{a}=\mathrm{b}=79.10 \AA$, $\mathrm{c}=37.90 \AA$. We downloaded the atomic coordinates for this structure and removed the solvent molecules. This dehydrated structural model was used to find a molecular replacement solution using the program Phaser in the CCP4 suite.22, 23 The model was built, adjusted and solvent molecules placed using Coot. ${ }^{24}$ Refinement was carried out with REFMAC5. ${ }^{25}$ The atomic model and electron density maps displayed in Figure 5 were made with PyMol. ${ }^{26}$

\begin{tabular}{|c|c|}
\hline \multicolumn{2}{|c|}{ Table 3a. Lysozyme Structure Refinement } \\
\hline Space Group & $\mathrm{P}_{3} 2_{1} 2$ \\
\hline Cell dimensions $(\AA)$ & $\mathrm{a}=\mathrm{b}=78.98, \mathrm{c}=36.85$ \\
\hline Resolution $(\AA)$ & $20-1.80$ \\
\hline$R_{\text {work }}$ & 0.1891 \\
\hline$R_{\text {free }}$ & 0.2368 \\
\hline rms bond lengths $(\AA)$ & 0.023 \\
\hline rms bond angles $\left(^{\circ}\right)$ & 1.77 \\
\hline \multicolumn{2}{|c|}{$\begin{array}{l}\mathrm{R}_{\text {factor }}=\sum_{\text {hkl }}|| F_{o}|-| F_{\mathrm{c}}|| / \Sigma_{\text {hl }}\left|F_{o}\right| \\
\mathrm{R}_{\text {free is is the }} R_{\text {factor }} \text { for } 4.8 \% \text { of the data not used in refinement. } \\
\mathrm{R}_{\text {work }} \text { is the } \mathrm{R}_{\text {factor }} \text { for } 95.2 \% \text { of the data used in refinement. }\end{array}$} \\
\hline
\end{tabular}
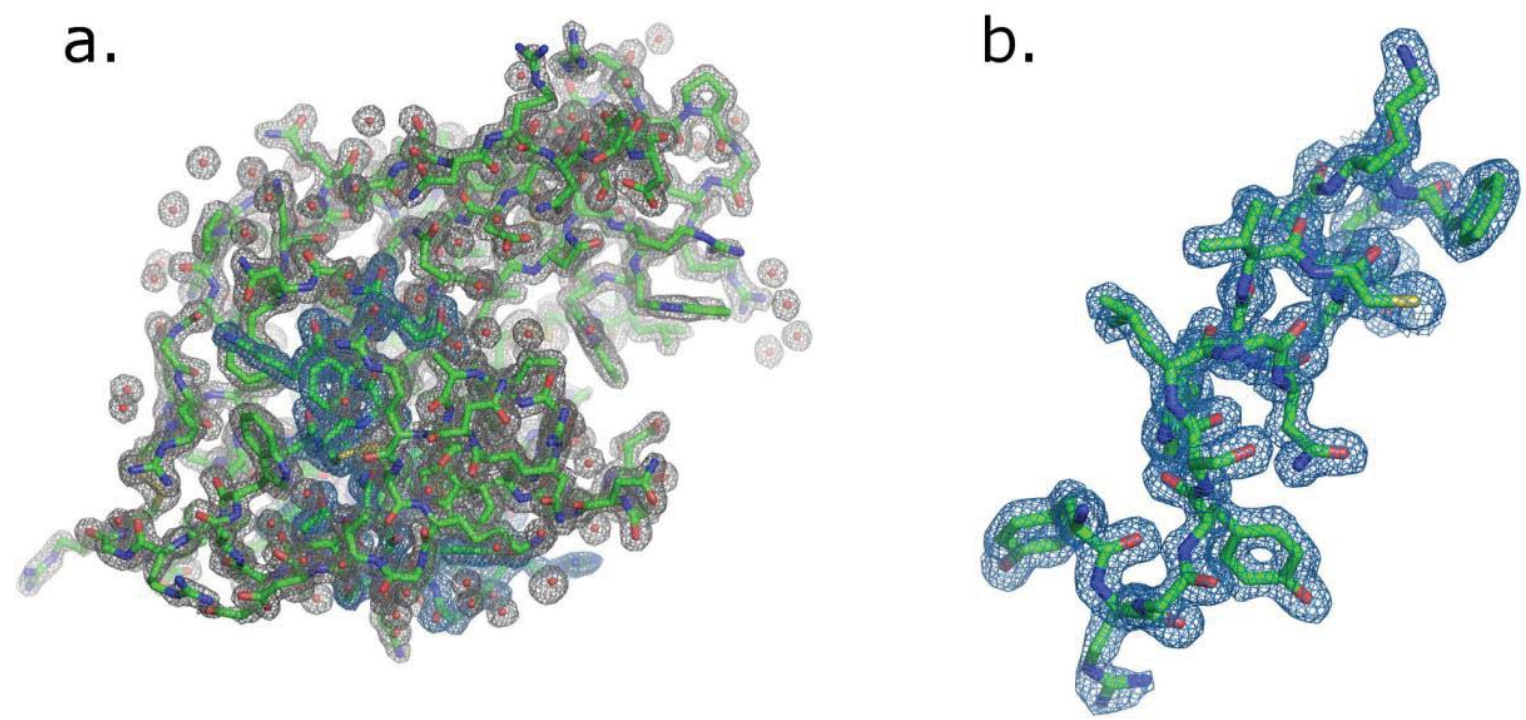

Figure 5. 2Fo-Fc electron density map contoured at $1 \sigma$ is superimposed on the refined atomic model of lysozyme in stick form with carbon atoms green, nitrogen blue, sulfur yellow, and oxygen red. a. Entire lysozyme molecule including ordered water molecules modeled as single oxygen atoms due to the data resolution. $\mathbf{b}$. An $\alpha$-helix from the model shown individually to better illustrate the quality of the map.

\section{Crystal structure solution and refinement of xylanase}

The unit cell parameters of the xylanase crystal were similar to an orthorhombic form of this enzyme in the PDB (ID 4HKL). ${ }^{7}$ The space group for this entry is $\mathrm{P} 2{ }_{1} 2_{1} 2_{1}$ with cell dimensions of $\mathrm{a}=48.3, \mathrm{~b}=59.0 \AA, \mathrm{c}=69.7 \AA$. The atomic coordinates for this structure with the solvent molecules removed was used as a search model for molecular replacement using Phaser in the CCP4 suite. ${ }^{22,23}$ The model was adjusted, side chain rotamers were checked and fitted into the electron density map, and solvent molecules were added using Coot. ${ }^{24}$ Refinement was carried out with REFMAC5. ${ }^{25}$ The atomic model and electron density maps displayed in Figure 6 were made with PyMol. ${ }^{26}$ 
Table 3b. Xylanase Structure Refinement

\begin{tabular}{|c|c|}
\hline Space Group & $\mathrm{P} 2{ }_{1} 2_{1} 2_{1}$ \\
\hline Cell dimensions $(\AA)$ & $\mathrm{a}=48.34, \mathrm{~b}=58.78, \mathrm{c}=69.70$ \\
\hline Resolution $(\AA)$ & $45-1.78$ \\
\hline $\mathrm{R}_{\text {work }}$ & 0.1584 \\
\hline $\mathrm{R}_{\text {free }}$ & 0.1971 \\
\hline rms bond lengths $(\AA)$ & 0.020 \\
\hline rms bond angles $\left(^{\circ}\right)$ & 1.79 \\
\hline
\end{tabular}

$\mathrm{R}_{\text {factor }}=\Sigma_{\mathrm{hkl}}|| \mathrm{F}_{\mathrm{o}}|-| \mathrm{F}_{\mathrm{c}}|| / \Sigma_{\mathrm{hkl}}\left|\mathrm{F}_{\mathrm{o}}\right|$

$\mathrm{R}_{\text {free }}$ is the $\mathrm{R}_{\text {factor }}$ for $5.1 \%$ of the data not used in refinement.

$\mathrm{R}_{\mathrm{work}}$ is the $\mathrm{R}_{\text {factor }}$ for $94.9 \%$ of the data used in refinement.
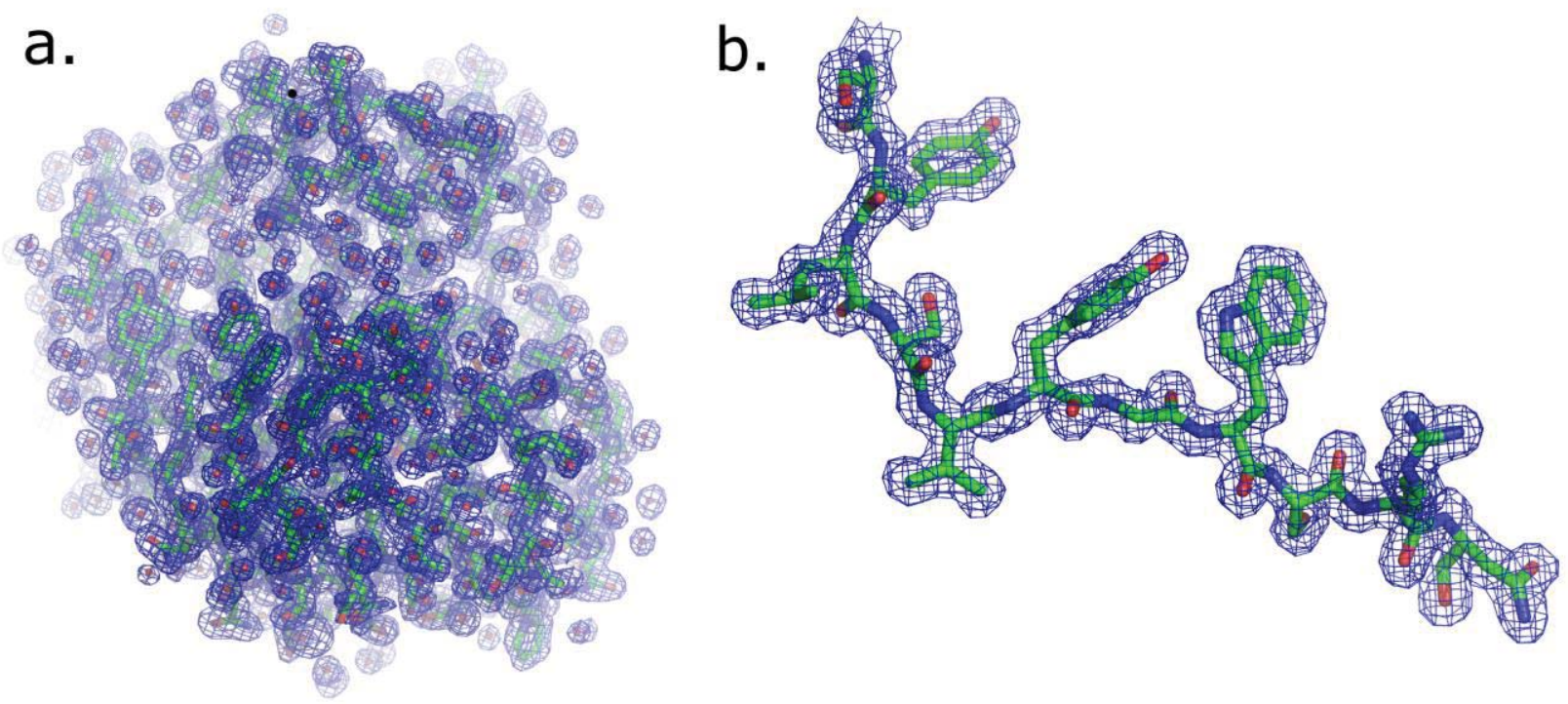

Figure 6. $2 \mathrm{Fo}-\mathrm{Fc}$ electron density map contoured at $1 \sigma$ is superimposed on the refined atomic model of xylanase in stick form with carbon atoms green, nitrogen blue, and oxygen red. a. Entire xylanase molecule including ordered water molecules modeled as single oxygen atoms. b. A $\beta$-strand (residues 72 to 82 ) from the model shown individually to show map quality.

\section{CONCLUSIONS}

Our experiments demonstrate that the Bruker AXS SMART BREEZETM system equipped with a copper sealed tube and Oxford Cryostream is an effective instrument for data collection from these protein crystals with smaller unit cells. We were able to collect a 40-fold redundant dataset from a lysozyme crystal with an average I/ $\sigma \mathrm{I}$ of 26.6 in a total time of 53 hours. A good quality 8 -fold redundant dataset could have been collected in less than half a day, which underscores the efficiency of this system regarding macromolecular crystals.

Our xylanase project further demonstrates the feasibility of collecting complete, redundant, moderately high-resolution datasets on these protein crystals in a short time period, and that this system has the potential to provide a successful experience in protein crystallography for students in an academic biochemistry laboratory. Although longer exposure times would have likely improved the $\mathrm{R}_{\text {symm }}$ statistics of the data, our five-hour data collection strategy proved sufficient for a structure solution using the technique of molecular replacement, and resulted in a well-defined electron density map that was easily interpreted (Figure 6), and a molecular model with good stereochemistry and agreement with the experimental data. This seems like a very reasonable exercise to incorporate into an academic lab to provide a nice introduction to the field of protein crystallography, with a reasonably high chance of success for students. 
Using this system we are able to address a wide range of crystallographic projects, ranging from simple ionic compounds and organic small molecules to larger macromolecules like small proteins. Our work shows that the signal to noise ratio at close distances is sufficient for these protein standards using the air-cooled BREEZETM detector. X-ray systems for protein crystals have not previously incorporated this detector which is cooled to only $-25^{\circ} \mathrm{C}$ using an air-cooled Peltier device. Often, $\mathrm{X}$-ray systems are instead equipped with the APEX IITM, a more expensive detector with an identical CCD chip, cooled to $-50{ }^{\circ} \mathrm{C}$ to minimize dark current, and requiring a water/ethylene glycol heat exchange system. In addition to being less expensive, the aircooled BREEZETM detector has significantly lower maintenance compared to this water/glycol-cooled detector. The cost of our system is less than half that of a dedicated protein data collection system, yet it still provides an effective platform for analysis of protein crystals with unit cells of up to at least 80 Angstroms. We look forward to future experiments analyzing protein crystals with larger unit cells, to assess the efficiency of data collection when the detector is pushed to greater distances to resolve more tightly-spaced diffraction patterns. The ability to collect data on such a wide range of samples, under a wide range of temperatures provides a relatively cost-effective and powerful analytical tool for academic labs and for a wide variety of undergraduate research projects at Southern Utah University.

\section{ACKNOWLEDGEMENTS}

We gratefully acknowledge funding from the Undergraduate Research and Scholarship Program (UGRASP) at SUU. We also thank the Department of Physical Science and The Walter Maxwell Gibson College of Science and Engineering for generous support of the X-ray diffraction facility at SUU. We are also grateful for the L.S. and Aline W. Skaggs Center for Health and Molecular Sciences and the Edward \& Shirley Stokes Open Chemistry Laboratory for housing the X-ray system.

\section{REFERENCES}

1. The Official Web Site of the Nobel Prize. Physics Prizes and Laureates; Complete List, Nobelprize.org/nobel_prizes/physics/ (accessed Oct 2016)

2. Freidrich, W., Nipping, P.I., and Laue, M. (1912) Interferenz-Erscheinungen bei Röntgenstrahlen. Bayerische Akad $d$ Wiss zu München, Sitzungsber math-phys Kl 303-322.

3. Bragg, W.L. (1913) The Diffraction of Short Electromagnetic Waves by a Crystal. Proc Camb Phil Soc 17, 43-57.

4. Bragg, W.L. (1914) The Structure of Some Crystals as Indicated by their Diffraction of X-rays. Proc R Soc Lond A89(610), 248277.

5. Rhodes, G. (2006) Crystallography Made Crystal Clear. Burlington, MA: Academic Press Publications.

6. Rupp, B. (2010) Biomolecular Crystallography: Principles, Practice, and Application to Structural Biology. Garland Science, Taylor \& Francis Group.

7. Berman, H.M., Westbrook, J., Feng, Z., Gilliland, G., Bhat, T.N, Weissig, H., Shindyalov, I.N., and Bourne, P.E. (2000) The RCSB Protein Data Bank, www.rcsb.org. Nucleic Acids Research 28, 235-242.

8. Kendrew J.C., Bodo G., Dintzis H.M., Parrish RG, Wyckoff, H., and Phillips, D.C. (1958) A three-dimensional model of the myoglobin molecule obtained by x-ray analysis. Nature 181, 662-666.

9. Kendrew, J.C., Dickerson, R.E., Strandberg, B.E., Hart, R.G., Davies, D.R., Phillips, D.C., and Shore, V.C. (1960) Structure of myoglobin: A three-dimensional Fourier synthesis at 2 A. resolution. Nature 185, 422-427.

10. Perutz, M.F., Rossman, M.G., Cullis, A.F., Muirhead, H., Will. G., and North, A.C. (1960) Structure of haemoglobin: a threedimensional Fourier synthesis at 5.5-A. resolution, obtained by X-ray analysis. Nature 185, 416-422.

11. Perutz, M.F., Muirhead, H., Cox, J.M., and Goaman, L.C. (1968) Three-dimensional Fourier synthesis of horse oxyhaemoglobin at $2.8 \AA$ resolution: the atomic model. Nature 219, 131-139.

12. Personal communication, Larry Hanright, Field Service Supervisor, Bruker AXS.

13. Alderton, G., Ward, W.H., and Fevold, H.L. (1944) Isolation of lysozyme from egg white. J Biol Chem 157, 43-58.

14. Blake, C.C.F., Koenig, D.F., Mair, G.A., North, A.C., Phillips, D.C., and Sarma, V.R. (1965) Structure of hen egg-white lysozyme. A three-dimensional Fourier synthesis at 2 Angstrom resolution. Nature 206, 757-761.

15. Diamond, R. (1974) Real-space refinement of the structure of hen egg-white lysozyme. J Mol Biol 82, $371-391$.

16. Torronen, A., Rouvinen, J., Ahlgren, M., Harkki, A., and Visuri, K. (1993) Crystallization and preliminary X-ray analysis of two major xylanses from Trichoderma reesei. J Mol Biol 233, 313-316.

17. Watanabe, N., Akiba, T., Kanai, R., and Harata, K. (2006). Structure of an orthorhombic form of xylanase II from Trichoderma reesei and analysis of thermal displacement. Acta Cryst D Biol Cryst 62, 784-92.

18. Alderton, G. and Fevold, H.L. (1946). Direct crystallization of lysozyme from egg white and some crystalline salts of lysozyme. J Biol Chem 164, 1-5.

19. LYSOZYME.CO.UK (2006) bttp:// lysozyme.co.uk/ crystallization.php (accessed Jan 2012) 
20. Bruker AXS (2013) SAINT, Version 8.32B, Bruker AXS Inc., Madison, Wisconsin, USA.

21. Bruker AXS (2012) SADABS, Version 2012/1, Bruker AXS Inc., Madison, Wisconsin, USA.

22. McCoy, A.J., Grosse-Kunstleve, R.W., Adams, P.D., Winn, M.D., Storoni, L.C., and Read, R.J. (2007) Phaser crystallographic software. I Appl Cryst 40(4), 658-674.

23. The CCP4 suite: programs for protein crystallography (1994) Acta Cryst D Biol Cryst 50(5), 760-763.

24. Emsley, P. and Cowtan, K. (2004) Coot: model-building tools for molecular graphics. Acta Cryst D Biol Cryst 60, $2126-2132$.

25. Murshudov, G.N., Vagin, A.A., Dodson, E.J. (1997) Refinement of macromolecular structures by the maximum-likelihood method. Acta Cryst D Biol Cryst 53(P3), 240-255.

26. The PyMOL Molecular Graphics System, Version 0.99 Schrödinger, LLC.

\section{ABOUT THE STUDENT AUTHORS}

Christiana Standler graduated from Brigham Young University-Hawaii (BYU-H) in April of 2014 with a B.S. degree in PreProfessional Biology. In March 2015, she presented her multivariate statistics research from BYU-H at the International Convention of Psychological Science in Amsterdam. Christiana completed further undergraduate coursework at Southern Utah University (2014-2015) where she continued her research interests. Christiana began her MSc degree in Human Biology at the University of Copenhagen in September of 2015 and is expected to graduate in August 2017. She is currently completing her master's thesis at Bioneer A/S in Hørsholm, Denmark, with a focus on hepatocyte differentiation of human induced pluripotent stem cells.

Gary Blake Overson graduated from SUU in the spring of 2016 and is currently applying to matriculate into medical school for the fall of 2017. He is presently employed through The Classical Academies in Southern California, working as a high school chemistry instructor/tutor. He enjoys helping his students learn and understand the basics of chemistry while building their foundation in this subject. He enjoys spending his free time relaxing and taking care of his family. He desires to attend and complete medical school, and to help bridge the gap between the research being completed and the treatment of individual people.

Cody Black graduated from Dixie State University in May of 2009 with an A.S. then continued his education at SUU. He is currently working on his Pharm.D. at the University of New England in Maine, where he is honored to be recognized as a Rho Chi member, as well as fellowshipping on several research topics funded by NSF, such as the mechanism of antimicrobial drugefflux activity across bacterial inner-membranes. He is also a member/leader of various organizations focused on addressing current health disparities and public education. He enjoys educating the community and colleges, and plans on pursuing a postgraduate education after graduating from UNE in May of 2018. Outside of his various educational and community outreaching activities, he relishes his time with his wife and children by exploring the beauty of the outdoors.

Guizella Rocabado graduated from Aims Community College in May of 2009 with an A.S. degree and was awarded the President's Medallion. She continued her education at SUU where she earned a B.S. degree in biology and a B.S. degree in chemistry in May of 2012. She continued her studies and earned a M.S. degree in medicinal chemistry from the State University of New York at Buffalo (UB) in September of 2014 where she researched the effect of tetraurea macrocycles on G-quadruplex DNA. She was awarded the Schomburg Fellowship for underrepresented students as well as membership in the Collaborative Learning and Integrated Mentoring in the Biosciences (CLIMB) program at UB during her graduate work. She is currently working as an assistant professor of chemistry at SUU and is expected to start her doctorate work in chemical education at the University of Southern Florida in the Fall of 2017.

\section{PRESS SUMMARY}

Our experiments demonstrate that the Bruker AXS SMART BREEZE ${ }^{\text {TM }}$ system equipped with a copper-anode sealed tube and Oxford Cryostream is an effective instrument for data collection from protein crystals of cell dimensions of at least up to 80 Angstroms. The cost of this system is less than half that of dedicated protein data collection systems, yet still provides an effective platform for protein crystal analysis in addition to its primary role in chemical crystallography. 